\author{
PIOTR KRAJEWSKI \\ Faculty of Law and Administration \\ University of Warmia and Mazury in Olsztyn \\ ORCID ID: 0000-0001-7233-899X
}

\title{
ARTIFICIAL INTELLIGENCE - (UN)JUSTIFIED AMBITIONS AND (NEEDLESS) FEARS
}

\begin{abstract}
Artificial Intelligence is undoubtedly one of the greatest achievements of the human intellect; in a sense, it has a creative character, because here one being (i.e. a human) gives (well, maybe not quite yet, but almost) independent life to a different being. The curiosity where this will lead us humans seems to be greater than the questions of anxiety that arise on this occasion. These questions are very diverse and concern almost all aspects of human activity. The interest in the development of new technologies connected with artificial intelligence and with the future is perfectly justified, but what about the risk that is inherent in every invention; moreover, a risk that is usually proportional to its actual importance?

This paper contains many questions, not at all original, expressing anxiety, for which we still do not have answers - and probably will not for a long time.
\end{abstract}

KEYWORDS: artificial intelligence, human rights, risk of social change

\section{INTRODUCTION}

The effects of using artificial intelligence depend on the software and the data fed to it. To some extent, therefore, it is conditioned by the intentions of the originators. Some subjectively or objectively important aspects may (for example) not be included in or handled by a programmed algorithm in order to intentionally reproduce structural errors. The use of real data to illustrate reality perpetuates the belief that AI (artificial intelligence) has agency and is precise and independent in action, even if, in fact, it is not (this is called 
math-washing). Incorrectly programmed, it could therefore lead to the issuing of decisions regarding (say) employment, granting loans, or criminal proceedings, which discriminate by ethnicity, gender, health, or age. Or it may find itself in risky contraposition to legal actions aimed at the protection of personal data or private life (as is the case in face recognition systems ${ }^{1}$ or profiling, combining them with numerous other information obtained without the knowledge and consent of the person concerned). It can also be used to create false but extremely realistic images, documents, videos and statements (called deepfakes) to defraud, mislead, damage reputations, and undermine the trust of public and private individuals, e.g. in decision-making processes or elections.

There are therefore many possibilities (the existence of which we may not yet suspect, and whose boundaries are set - it seems - only by imagination), but they are accompanied by more and more doubts, not only related to their direct (let us call it) "positive" or "negative" application, but with comprehensive, multi-faceted socio-organizational, cultural, and civilization changes, and thus dynamically developing and constantly occurring processes that we already have to contend with.

Artificial intelligence can be considered - with reasonable confidence - the challenge of the age both for societies as organized entities and for the individuals who constitute them, for state authorities, for international institutions and organizations (including the current leadership of the European Union) because it will undoubtedly play a fundamental role in the IT transformation of our civilization that has already been initiated. This is not a topic for futurologists because today it is difficult to imagine a world without $\mathrm{AI}$ in its various manifestations, without its participation in the creation of goods and services; moreover, it itself is a readymade good and service offered to the consumer. Similar changes are taking place in labour, finance, health, agriculture and the military. It has a central place in the European and national "New Deals" and in the post-Covid economy².

1 Remote temperature monitoring and facial recognition. Zamel-lead your business into the future, https://zamel.com/pl-PL/centrum-prasowe/pl-pl/artykuly/zdalny-pomiar-temperatury-i-rozpoznaniu-twarzy-zamel (20/06/2021).

2 The post-crisis New Deal for Europe, https://cordis.europa.eu/article/id/238746-a-postcrisisnew-deal-for-europe/en (24/03/2021). 


\section{AN ETHICAL LAYER FOR REGULATIONS GOVERNING AI DEVELOPMENT}

A frequent revisiting of the ethical aspects of artificial intelligence, robotics and related technologies, of liability for possible damage caused by them, and the need to revise the Directive on liability for defective products ${ }^{3}$ is intended to prepare the way for specific regulations defining the future of this sector. As a result, the EU Parliament adopted three resolutions specifying how the EU can simultaneously best regulate $\mathrm{AI}$ issues and contribute to the development of innovation, as well as raise ethical standards and trust in modern technologies.

The first resolution, the European Parliament resolution of 20 October 2020 $(2020 / 2012(\text { INL }))^{4}$, deals with what can be said to be "constitutive" issues, as it makes recommendations to the Commission on a framework for the ethical aspects of AI, robotics, and related technologies. The resolution concerns guaranteeing safety, transparency and accountability, avoiding prejudices and discrimination, strengthening environmental protection and respecting fundamental rights.

The second resolution includes, among others, recommendations to the Commission on an AI civil liability regime (2020/2014(INL) $)^{5}$. The third resolution concerns intellectual property law in the field of artificial intelligence technology development (2020/2015(INI) $)^{6}$. Among the important problems to be solved is also determining who should hold the intellectual property rights to a product completely realized by artificial intelligence.

These, and perhaps other reasons, prompted the EU Commission to present a complete set of ethical principles for the legal framework, along with legal obligations for the development, dissemination and use of artificial

3 Council Directive 85/374/EEC of 25 July 1985 on the approximation of the laws, regulations and administrative provisions of the Member States concerning liability for defective products. 4 European Parliament resolution of 20 October 2020 with recommendations to the Commission on a framework for the ethics of AI, robotics, and related technologies (2020/2012(INL)), https://www.europarl.europa.eu/ doceo / document / TA-9-2020-0275_PL.html (March 24, 2021).

5 European Parliament resolution of 20 October 2020 with recommendations to the Commission on a civil liability regime for artificial intelligence (2020/2014(INL)), https://www.europarl. europa.eu/doceo/document/TA - 9-2020-0276_PL.html (March 24, 2021).

6 European Parliament resolution of 20 October 2020 on intellectual property rights in the field of AI technology development (2020/2015(INI)), https://www.europarl.europa.eu/ doceo/document/TA-9-2020-10-20_PL.html (March 23, 2021). 
intelligence, robotics and related technologies, including software, algorithms and data used or produced by these technologies. This "system" of rules and principles is to be based on EU law, the Charter and international human rights law and, above all, to apply to high-risk technologies in order to work out uniform regulations for the entire $\mathrm{EU}^{7}$. This should allow enterprises to bring innovative products to the market and thus open up new opportunities for them. The second goal - accompanying the first one - is to guarantee the protection of the values promoted by the EU by incorporating (already at the design stage) the principles of ethics into the ongoing processes of the multidirectional development of AI systems. Such "saturation" of the normative framework with ethics would become an added value, giving the EU a unique competence advantage when introducing competitive products to the IT market. The intention is ambitious, the problem is far from trivial, and the future is uncertain.

\section{A FUTURE IN QUESTION}

The acceleration of scientific and technological development that has taken place since the mid-twentieth century must have, and has already led to, far-reaching changes in the life and organization of all human societies in the world - some lost their previous position and international importance, others regained it, and still others were decidedly strengthened. In general, although obviously to a different extent, the wealth of countries has increased, and so has the efficiency of a constantly intensifying economy. The lives of people forced to adapt to new technologies and forms of management have also changed significantly. Simply put, it can be said that everything is gaining momentum. This is the effect of the increased effectiveness of human work but, above all, of the intellect. The technologization of virtually all sectors of economic activity is a result of this acceleration. It allows us to gradually replace limited human capacity with machines. They are "armed" with artificial

7 Title 1 of the European Parliament resolution of 20 October 2020 with recommendations to the Commission on a framework for the ethics of AI, robotics, and related technologies (2020/2012(INL)), https://www.europarl.europa.eu/doceo/document/TA-9-2020-0275_ PL.html\#title1 (March 24, 2021). 
- an imitation of human - intelligence, they are able to work much more and more accurately, and the results (looking through the lens of economic indicators) are more than encouraging, sometimes even thrilling. However, is this all we can, and should, take into account, and that should guide us? The main question, along with others that appear immediately afterwards, is the question about the place of humans in the world they create in this way. Reason - whether obtained from 'on high' or evolutionarily developed - which initially served to invent and perfect simple tools to improve the quality of life, is now somehow passed on by the human creator to their own product. What is the purpose of this? This is an important question, and even more importantly, what consequences do or might follow? Are there areas of social and individual life that are excluded from this, and therefore will remain in the hands and under full "control" of people?

In this question, there is no concern (although it cannot be completely ruled out) about the hypothetical "take over" of the world by artificial intelligence like in science fiction tales, but there is rather a concern for the future of both the world and humanity. In connection with the already initiated "reformatting" of civilisation, it is necessary to ask about the place, the durability and, in general, about the existence of traditional (in the sense of centuries-old, cultivated and life-proven) values in a world run by microprocessors ${ }^{8}$. What position in the changing hierarchy of beings (expanded to encompass the new ones) have humans set for themselves to maintain or to gain? What will be (again: among new intelligent beings) the extent of human participation in decision-making and transformation processes? What role will people play in this future? After all, already being the supreme being of all, it would be nonsense for humans to aspire to a position higher still (unless the goal is to reject the barely won equality before the law). In the context of the "collective interest" of the species, this would be pointless, but for the "restless" ambitions of individuals, it may be an opportunity that - thanks to highly specialized knowledge and the use of AI - will allow some to stand above the average or the normal; no longer above other beings, but above other people.

8 Indellicato, M. (2016). The ethical foundation of human rights., The selected contemporary aspects of human rights (pp. 75-82). WSGE. 
This is a very real temptation, and its fulfilment would not require a justification; it would be a fait accompli.

Moreover, artificial intelligence is already contributing to the gradual differentiation of people; it is becoming a source of new forms of persistent inequality. This time, it is taking place not through the destruction and brutality of force but by gradually gaining an advantage over the technologically unresponsive. It is not even difficult. In a world where vital goods are slowly becoming scarce, access to them becomes crucial for the future. Disproportions in this regard will certainly grow much greater than they are at present. Therefore, it makes sense to focus on the competitive effectiveness of acquisition and not the power of destruction. Even now, there is sometimes a strong impression that talking about equality and solidarity is becoming an anachronism.

Here we come to the question about the future of human rights, which we now, only since half a century ago, consider to be the pinnacle of humanities and law. Will they make sense in a world where the scope of human competence and decision-making may be limited only to the most basic and trivial issues of survival? On what basis and on what criteria will the issues of respecting and/ or violation of inalienable rights of the individual (or those we now recognize as such) be resolved? Will human rights be real or also virtual in the virtual world? Who will ensure that they are obeyed? Will their violation in the real world have consequences in the virtual world and vice versa? Who will settle disputes? Will we implement an emotionless system to objectify the judgment and impartially assess documents and facts? Will the microprocessor decide the innocence or guilt of a person or institution, more or less like a pacemaker or insulin pump makes discernments now?

As we can see, there are many questions, and one gets the impression that their diversity is limited only by our imagination. Sometimes they seem downright absurd and so fantastic that we wonder if they should arouse anxiety or just curiosity.

It is certain that the changes will be rapid and far-reaching and, certainly, not everyone will keep up with them because they cannot already. High skill levels will result in the fact that "latecomers" will be gradually excluded. Their auto-marginalization due to a lack of education, helplessness, frustration, powerlessness and multiple subjective and objective internal and external factors will do the rest. Inequalities will divide and antagonize societies. Relationships 
between people will become significantly polarized; disproportions in skill will allow contact only with "equals". The main part of interpersonal relations will shift from real meetings in one place and time to the virtual space of anonymised individuals, whose position will be determined by a non-human technical factor - for example, the availability of equipment and the ability to use it. Virtualisation of meetings will become a necessity, if only because of the obligation to keep distance caused by epidemiological threats or the need for simultaneous participation of many interlocutors and exchange of information over long distances; we are already dealing with the beginnings of such a scenario - digital exclusion is a reality. If IT discrimination is to become a common fact, it must be accompanied by the spirit of legislative changes that would sanction it and give it hallmarks of universal acceptance. This will require profound changes in both philosophy and in ontology relating to the law, which would codify the new order of things. But will it still be law in the present sense of the word? And if it is law, will it fit the measure of (every) human being, or at least will it be pro-human?

\section{CyBERSOCIETY BETWEEN ANARCHY AND THE RULE OF LAW}

Cyberspace is no longer a hobby of IT enthusiasts, it is a reality that not everyone agrees to, but that everyone is forced to enter. It is said that the line between the real and the virtual world is blurred. Even state institutions, which are still very present, have, in fact, transferred a significant part of their activity into the sphere of the digital world. Why? For many legitimate reasons, of course - which, however, do not always convince everyone. It is so because it is cheaper, faster, more effective, more modern, more economical, more convenient, etc.

One of the issues discussed today is the place of the community, which in its organization must be somewhere between the extremes of anarchy and the rule of law. How do we understand this? Of course, this can be interpreted in different ways. Much depends on the attitude. The starting point here is the assumption that there is, or will soon be, something that is already called cybersociety. Leaving aside the question of what this cybersociety will be and whether it would be a community in a sociological, legal, cultural, historical or religious sense, or at 
least in the common (intuitive) sense of the word, it provokes an attempt to answer another question: which organisation will it be closer to: anarchy or the rule of law? The first option is unlikely to be assumed by anyone, or at least it is not the goal of aspirations. The second option leads us to scrutinise the rule of law, or the rule of reason for the good of that society, for the good of humanity. Anarchy is a form of disordered lawlessness. But the rule of law may also turn out to be a form of lawlessness detached from the ontological truth about humans (in this case, ordered) - even a form of oppressive lawlessness by the majority. Because the will of the majority determines the form of government, like any other social, legal, or state order, democracy usually presupposes some form of control of people and institutions. How would such control of cybercitizens look like in a cyberstate? Probably it would be nothing but total, because the tools created for this purpose predict and will allow such control. Would one agree to this? I suppose there will not be a choice. Will it be possible to justify it? Of course, for example, with concern for individual and collective safety. Will this be sufficient? Certainly, because security is a good highly valued by everyone. Therefore, for the very sense of security, a person is ready to give up many things (and even some part of their individuality and freedom over which someone/something will take control). The controllers, therefore, by gaining, gathering, processing and using knowledge, gradually take power. Are there any limits to this? It does not seem so. We can call it democracy as long as consent comes from the majority, but will it be the consent of informed people who retain their individual freedom of choice, or will participation in decision-making processes be conditioned by external factors? For example, the need to purchase a smartphone, computer, update software, enter the required data or fingerprints into the database, remember and enter a PIN during any operation, enter the username, password, etc. - all closely guarded data, which are nevertheless known to someone and controlled by something/ someone (as it is with algorithms searching for suspicious banking transactions). Thus, by wanting more independence, we will lose this independence to those who control our freedom. A trivial question at this point: will there be someone who controls those who control?

From the perspective of a cyberstate, will the rights of the citizen and, more broadly, human rights become a virtual reality? An immaterial reality, one that exists but, in fact, does not exist? After all, what has until recently, or what is, for the time being, freedom and law, may soon become a restriction or even 
a violation of the law. This particularly applies to the right to the confidentiality of correspondence, to the protection of personal data, to the retention of one's identity and, in general, the rights of the so-called second and third generation. After all, the privacy of the web portals viewed, the preferences of the TV programs watched, the place of stay, the frequency and size of transactions, the routes travelled - all this privacy is already evident fiction, soon to be joined by the privacy of biomedical and other data. Is the state interested in broadening this level of control? From an institutional point of view, certainly yes, because the obtained information and the use of artificial intelligence allow it to make decisions. What do we get in exchange? A sense of order, certainty, predictability, security - in a sense.

\section{SECURITY AND CULTURE}

Security is certainly one of the primary, basic needs, the satisfaction of which allows a person, first of all, to maintain life, health, and to develop ${ }^{9}$. It is, therefore, the overriding need of the individual and a constitutive need of states and international systems. It has a subjective character and is characterized by no risk of losing something that a person especially appreciates ${ }^{10}$. It gives a sense of certainty and continuity of existence, guarantees its preservation and a chance for improvement ${ }^{11}$. Its curtailment or absence causes anxiety and a sense of threat ${ }^{12}$.

Artificial intelligence, robotics, and related technologies are qualitatively quite new. Something that - although it is only developing - to some extent already constitutes a danger. After all, we have been talking for years about cybersecurity, cyberbullying, cyberterrorism, cyber threats, etc. What does it mean? It means that we are ill-equipped to handle something which - as we

9 Winiarski, M. (2003). Security in the local environment, in: Encyklopedia pedagogiczna XXI wieku [Pedagogical Encyclopaedia of the 21st Century], Warsaw, vol. I, pp. 343-347.

10 Domański, Z. (2015). Bezpieczeństwo [Security], in: P. Chodak (ed.), Leksykon bezpieczeństwo. Wybrane pojęcia [Lexicon of security. Selected concepts], Józefów, p. 7.

11 Dziurzyński, K. (2015). Poczucie bezpieczeństwa [Sense of security], in: P. Chodak (ed.), Leksykon bezpieczeństwo. Wybrane pojęcia [Lexicon of security. Selected concepts], Józefów, pp. 148-149.

12 Zawisza, J. (2015). Cyberspace as a threat to state security, Journal of Modern Science 4/27/2015, pp. 403-416. 
constantly assure ourselves - is only beginning, and there is no assurance at this point that these are encyclopaedic terms that testify to anticipatory actions being undertaken. The fact that there is some risk behind novelty should not be surprising because every human imperfection becomes an opportunity to be used by others, and not necessarily for good purposes. Forced civilisational transformations (whose nature is predominantly physical and material, caused by the necessity to use, or at least encounter, new technologies involving AI) shape a new individual and collective consciousness, and thus also (probably) a new culture, which, due to the dynamic nature of the changes, has little in common with its traditional understanding - like the entirety of human achievements produced in the general historical development or in its specific epoch, manifesting itself in a certain stability of general intellectual and spiritual assumptions ${ }^{13}$.

The distinguishing feature of cyberculture in the cyberage is its dynamism and, in its own way, questioning the achievement of previous ages; and these achievements are many. There is concern, for example, about undermining, and maybe even the necessity to give up, these rights, which we have been enjoying for only half a century ${ }^{14}$. These fears are probably justified, since we are already dealing with, for example, facial recognition technologies based on biometric data, automatic reading of registration numbers, identifying people on the basis of voice or heartbeat, lip-reading and behaviour prediction; it has become standard to detect financial fraud and terror financing, to monitor the contents of information appearing in the mass media, on social networks, and in private

13 Tatarkiewicz, W. (2016). O filozofii i sztuce [On philosophy and art], Warsaw 1986, pp. 148, 150; K.D. Kopeć, Digital participation in cultural heritage. The case of open Monuments crowdsourcing platform, Journal of Modern Science 1/28/2016, p. 4764.

14 Universal Declaration of Human Rights (1948); The European Convention on Human Rights (1950); International Human Rights Covenants (1966); Charter of Fundamental Rights of the European Union (2016) 
correspondence ${ }^{15}$. This primarily impacts the individual, and through them, interpersonal relations, undermining social life as we know it. Restrictions on freedom lead to the isolation of individuals who must be satisfied with a substitute of social life, limited to a virtual community ${ }^{16}$. An atomized society ceases to be a society in the current sense of the word. In its place, a global community is formed, the only common denominator of which will probably be species affiliation and the distinguishing feature of the IP number. What then about history? What about patriotism? What about art? The product of a new (global) society will be a new (equally globalized) culture. But will it - following the example of society - still be a culture in the sense we understand and know it today? Will it be a culture at all?

\section{DigitAL EXCLUSION}

It is difficult to say whether the greatest changes should be expected in the economic sphere or in the social and individual sphere because all areas of human life and activity are significantly interconnected and interdependent. Advances in technology are undoubtedly the most easily noticed; it does not take generations to see; it happens on an ongoing basis. Traditional crafts and professions are dying. Some of them are not even known for specific skills and requirements because we do not repair even the simplest items and devices but only replace them. On the other hand, there are new narrow specializations and professions gathering people with specific intellectual and personality requirements, their skills significantly exceeding the vast majority of people (e.g. programmers). It is a new, emerging class and simultaneously a new form

15 In the case of the ongoing fight against the effects of the SARS-CoV-2 pandemic, paradoxically, advanced technologies of surveillance of people, facial recognition, and collection of precisely personalized data are not effective if the government does not use them to inform the public, but in the first place to maintain the stability of the state system. Taiwan - for example - keeps the epidemic in check because it circulates information about the location of the infected in real time and provides their data on travel, activities, contacts, and social environment to hospitals, local governments, services, and a crisis centre. And all aggregate data is available publicly.

16 Separate research, going beyond the semantic framework of the dictionary entry, is required for the term "virtual community", which would answer, inter alia, whether this is/will be a community at all (similarly to culture) in the way we understand and know it today. 
of social domination. Not yet decisive and not ruling, but certainly managing. This class possesses the rare ability to reach information and the knowledge to sort, aggregate, interpret and use the acquired data in practice.

In the meantime, it is noted that investment capital (both domestic and international) is slowly shifting its focus, until recently to IT and mechatronics and now towards artificial intelligence. This requires a redesign of human society. However, with the current pace of change, is each generation capable of keeping up, based on its own resources and skills, since we are already dealing with a techno-skill stratification between generations? What are we going to do with the already clearly outlined intra-generational gap (as the intergenerational gap is insurmountable) among the youngest, caused by the disproportions of the material resources, all the more so as the lead group does not show the least intention to wait for the others? After all, this is - for some time now, a crawling, and now evident, though unnamed discrimination; this time it is IT, pushing to the margins of community life everyone who does not keep up with the innovations, who is not favoured by the circumstances, who is forced to suspend tracking changes in this area even for a time, or - for various reasons, e.g. poverty - does not have access to hardware and software. Thus, an elite is formed, whose distinguishing feature is not intellectual ability to broadly analyse the past and present in creating a future that brings everyone closer to the idea of humanism, but specific skills in using equipment and technical data processing. The question is: what should happen with the rest of the people, if today simply using the telephone, and even accessing it, is an insurmountable problem for them? Will the new, computerized world, or rather those who manage to join it, find at least a momentary need to reflect on the culpable (because it was conscious) exclusion of many others? Do we, intentionally or unknowingly agreeing to all these things, still have the right to talk about the humanization of life? Or maybe, by entrusting ourselves to algorithms, we have already turned towards its denial - towards dehumanization, keeping only the appearance of freedom, equality, brotherhood combined with the (hopefully not anachronistic) virtues of beauty, goodness and truth. In the juxtaposition of two worlds, the digital and the "analog" world, the former three values become more illusory than ever; the latter three, even more coveted. 


\section{REFERENCES}

Charter of Fundamental Rights of the European Union (2016).

Council Directive 85/374/EEC of 25 July 1985 on the approximation of the laws, regulations and administrative provisions of the Member States concerning liability for defective products. (OJ L 210, 07/08/1985)

Domański, Z. (2015). Bezpieczeństwo [Security], in: P. Chodak (ed.), Leksykon bezpieczeństwo. Wybrane pojęcia. [Lexicon of security. Selected concepts], Józefów, p. 7.

Dziurzyński, K. (2017). Poczucie bezpieczeństwa [Sense of security], in: P. Chodak (ed.), Leksykon bezpieczeństwo. Wybrane pojęcia. [Lexicon of security. Selected concepts], Józefów, pp. 148-149.

European Convention of Human Rights (1950)

European Parliament resolution of 20 October 2020 on intellectual property rights in the field of AI technology development (2020/2015(INI)), https://www.europarl. europa.eu/doceo/document/TA-9 - 2020-10-20_PL.html (March 23, 2021).

European Parliament resolution of 20 October 2020 with recommendations to the Commission on a framework for the ethics of AI, robotics, and related technologies (2020/2012(INL)), https://www.europarl.europa.eu/ doceo / document / TA-92020-0275_PL.html (March 24, 2021).

European Parliament resolution of 20 October 2020 with recommendations to the Commission on a civil liability regime for artificial intelligence (2020/2014(INL)), https://www.europarl.europa.eu/doceo/document/TA - 9-2020-0276_PL.html (March 24, 2021).

International Human Rights Covenants (1966).

Kopeć, K. D. (2016). Digital participation in cultural heritage. The case of open Monuments crowdsourcing platform, in: Journal of Modern Science 1/28/2016, pp. 47-64.

Tatarkiewicz, W. (1986). O filozofii i sztuce [About philosophy and art]. Warsaw.

The post-crisis New Deal for Europe, https://cordis.europa.eu/article/id/238746-apostcrisis-new-deal-for-europe/en (24/03/2021).

Universal Declaration of Human Rights (1948).

Winiarski, M. (2003). Bezpieczeństwo w środowisku lokalnym, [Security in the local environment], in: Encyklopedia pedagogiczna XXI wieku [Pedagogical Encyclopaedia of the 21st Century], Warsaw. vol. I, pp. 343-347.

Zawisza, J. (2015). Cyberprzestrzeń jako zagrożenie bezpieczeństwa państwa [Cyberspace as a threat to state security], in: Journal of Modern Science 4/27/2015, pp. 403-416. 